\title{
Nanoscale
}

\section{Zebrafish as a model system for characterization of nanoparticles against cancer}

\begin{tabular}{|r|l|}
\hline Journal: & Nanoscale \\
\hline Manuscript ID & NR-ART-10-2015-007289.R1 \\
\hline Drticle Type: & Paper \\
\hline Date Submitted by the Author: & 23-Nov-2015 \\
\hline Complete List of Authors: & $\begin{array}{l}\text { Evensen, Lasse; University of Oslo, Department of Biosciences } \\
\text { Johansen, Patrick; University of Oslo, Department of Biosciences } \\
\text { Koster, Gerbrand; University of Oslo, Department of Biosciences } \\
\text { Zhu, Kaizheng; University of Oslo, Department of Chemistry } \\
\text { Herfindal, Lars; Univeristy of Bergen, Department of Biomedicine } \\
\text { Speth, Martin; University of Oslo, Department of Biosciences } \\
\text { Fenaroli, Federico; University of Oslo, Department of Biosciences } \\
\text { Hildahl, Jon; University of Oslo, Department of Biosciences } \\
\text { Bagherifam, Shahla; University of Oslo, Department of Chemistry } \\
\text { Tulotta, Claudia; University of Leiden, Department of Tumour Biology } \\
\text { Prasmickaite, Lina; Oslo University Hospital Radiumhospital } \\
\text { Mrlandsmo, Gunhild; Oslo University Hospital Radiumhospital } \\
\text { Snaar-Jagalska, Boguslawa; Leiden University, IBL, Molecular Cell Biology } \\
\text { Griffiths, Gareth; University of Oslo, Institute of Biosciences }\end{array}$ \\
\hline
\end{tabular}




\section{Zebrafish as a model system for characterization of nanoparticles against cancer}

Lasse Evensen, ${ }^{\dagger, \perp}$ Patrick L. Johansen, ${ }^{\dagger, \perp}$ Gerbrand Koster, ${ }^{\dagger}$ Kaizheng Zhu, ${ }^{*}$ Lars Herfindal, ${ }^{\S}$ Martin Speth, ${ }^{\dagger}$ Federico Fenaroli, ${ }^{\dagger}$ Jon Hildahl, ${ }^{\dagger}$ Shahla Bagherifam, ${ }^{\star}$ Claudia Tulotta, "Lina Prasmickaite, ${ }^{\mathfrak{f}}$ Gunhild M. Mælandsmo, ${ }^{\mathfrak{f}}$ Ewa Snaar-Jagalska," Gareth Griffiths ${ }^{\dagger, *}$

'Department of Biosciences, University of Oslo, Blindernveien 31, 0371 Oslo, Norway, ${ }^{\dagger}$ Department of Chemistry, University of Oslo, Sem Sælands vei 26, 0371, Oslo, Norway, ${ }^{\S}$ Department of Biomedicine, University of Bergen, Jonas Lies Vei 91, 5009 Bergen, Norway, "Institute of Biology, Leiden University, Einsteinweg 55, 2333 CC Leiden, The Netherlands, ${ }^{£}$ Department of Tumour Biology, Oslo University Hospital Radiumhospital, Oslo Norway. ${ }^{\perp}$ These authors contributed equally.

Therapeutic nanoparticles (NPs) have great potential to deliver drugs against human diseases. Encapsulation of drugs in NPs protects them from being metabolized, while they are delivered specifically to a target site, thereby reducing toxicity and other side-effects. However, nonspecific tissue accumulation of NPs, for example in macrophages, especially in the spleen and liver is a general problem with many NPs being developed for cancer therapy. To address the problem of non-specific tissue accumulation of NPs we describe the development of the zebrafish embryo as a transparent vertebrate system for characterization of NPs against cancer. We show that injection of human cancer cells results in tumor-like structures, and that subsequently injected fluorescent NPs, either made of polystyrene or liposomes can be imaged in real-time. NP biodistribution and general in vivo properties can be easily monitored in embryos having selective fluorescent labeling of specific tissues. We demonstrate in vitro, by using optical tweezer micromanipulation, microscopy and flow cytometry that polyethylene glycol (PEG) coating of NPs decreases the level of adhesion of NPs to macrophages, and also to cancer cells. In vivo in zebrafish embryos, PEG coating resulted in longer NP circulation times, decreased macrophage uptake, and reduced adhesion to the endothelium. Importantly, liposomes were observed to accumulate passively and selectively in tumor-like structures comprised of human cancer cells. These results show that zebrafish embryo is a powerful system for microscopy-based screening of NPs on the route to preclinical testing.

\section{Introduction}

Cancer is a major global health problem and cancer therapy is painful and demanding for patients ${ }^{1}$. Current anti-cancer drugs are often highly toxic and have severe side effects, such 
as nausea, vomiting and loss of hair, and the prolonged systemic distribution causes a dramatic decrease in the quality of life in cancer patients ${ }^{2}$. Because high toxicity limits dose it is impossible to use the full therapeutic potential of anti-cancer drugs. Further, it is difficult to deliver anti-cancer drugs to tumors when they are distributed systemically in its free form; rapid excretion transports the drug out of the body, their often hydrophobic nature results in poor solubility and, finally, free drugs are prone to be metabolized before reaching the target ${ }^{3}$. As a consequence drugs must be given frequently in multiple rounds to assure drug levels above minimum therapeutic concentration in tumor tissues. Thus, more efficient cancer therapy associated with fewer side-effects is desirable.

The introduction of nanotechnology for cancer therapy has the potential to improve the efficiency of current anti-cancer drugs and quality of life in cancer patients during treatment. There are at least $23 \mathrm{NP}$-therapies that are either in clinical use or under clinical investigation ${ }^{4}$. The aim is to deliver anti-cancer drugs encapsulated inside NPs specifically to tumors and thereby increase the drug concentration at target sites and to reduce off-target toxic effects. Nanotherapies used in the clinic today have the capacity to reduce side-effects but in general they only provide therapeutic efficacy that is comparable to conventional cancer therapy ${ }^{5,6}$. This suggests that nanomedicine is still in its infancy.

The zebrafish (ZF) model has gained popularity over the past two decades as a model for human diseases, including cancer. This model supports growth of human cancer cell lines that show many similarities to the behavior of tumors in mammalian models such as mice ${ }^{7,8}$. Further, when zebrafish are exposed to carcinogens they develop tumors in virtually all organs with similar histology to human tumors ${ }^{9}$. Sequencing of the ZF genome has revealed that $70 \%$ of human genes have at least one ZF orthologue; thus, many of the same molecular and cellular components are involved in the initiation and development of diseases ${ }^{7,10}$. Moreover, since the ZF embryo lacks a functional adaptive immune system during its first month of development ${ }^{11}$, this system is increasingly being used to study exogenous human or mouse cancer cells to form tumors as there is no need for active suppression of the immune system to avoid rejection of injected human cells ${ }^{7,12-14}$.

An especially valued aspect of the ZF system is that the embryo is optically transparent and tissues can be imaged in detail down to the single cell level, a unique feature for a vertebrate research animal ${ }^{7}$. Consequently, the biggest advantage of this model for cancer research is that tumor growth can be studied by microscopic imaging at high resolution over time in a living organism ${ }^{15}$. This system allows exogenously injected human tumor cell growth and tumor formation to be monitored in real time, with high spatial and temporal 
resolution. The ZF optical transparency also enables in vivo studies of other fluorescent objects such as NPs. For example, binding of some NPs to endothelial cells has been described as an undesirable characteristic. However, with a few exceptions ${ }^{16-21}$ there has been little analysis of interactions of NPs with endothelial cells in vivo.

Most studies combining nanotechnology and ZF have focused on evaluation of toxicity, by assessing the potential toxic effect that NPs of different chemical composition have on normal development ${ }^{22-24}$. Regarding nanotherapy, Wagner et al. showed that antibody labeled gold NPs are able to specifically kill cancer cells in the ZF embryo. When heated by a short laser pulse, the gold NPs generated a plasmonic nanobubble which selectively killed the cancer cells ${ }^{25}$. However, in this case the cancer cells were pre-labelled with gold NPs before injection into the ZF embryo. Other studies have shown that NPs do have an effect on growth of cancer cells injected into zebrafish embryos. However, the NPs were introduced via bath-treatment and no evidence was presented to show presence of NPs in tumor-tissues ${ }^{26-28}$. Our interest here is to use the ZF embryo to facilitate the development of NPs against human cancer that accumulates in tumors after their injection in the circulatory system. We have previously shown that NPs encapsulating an antibiotic are effectively taken up by macrophages in ZF embryos and kill Mycobacterium marinum, the model bacteria for tuberculosis (TB) ${ }^{29}$. An important feature of this TB model-system is that the macrophages that take up the NPs are precisely the same cells where the mycobacteria reside. In stark contrast to TB, NPs for cancer therapy must be fabricated such that they avoid macrophage uptake and thereby stay as long as possible in the circulation to maximize the amount of NPs reaching the tumor. This so-called 'stealth' property of NP's is a major focus of research in all applications of NPs against cancer. The ultimate goal is to develop a so- called "magic bullet" having features such as the ability to leak out of the vasculature at the tumor site and accumulate in tumor tissues, followed by selective uptake into the cancer cells where the drug is released, thereby killing them ${ }^{30-33}$.

We introduce the ZF embryo model as a fast screening tool for the development of NP therapies against cancer. Transgenic ZF lines that selectively express fluorescent proteins in selective tissues, for example the vasculature or macrophages, provide highly sophisticated tools for precise and detailed observation of the role of these tissues in development of tumors, as well as a precise tool to evaluate NP biodistribution.

Here we show that coating of NPs with PEG reduces NP adhesion to macrophages in vitro. This effect of PEGylation was also assessed in vivo in the ZF embryo model and it was found that the PEG NPs showed increased circulation time, reduced macrophage uptake, and 
reduced affinity for the endothelium associated with the circulatory system. Further, we demonstrate in vivo that NPs having good circulation properties accumulate specifically in regions where human cancer cells reside. Together, this demonstrates the suitability of the zebrafish as an in vivo model to characterize the biodistribution of NPs, their circulation properties and the passive targeting of human tumor-like structures.

\section{Methods}

Nanoparticle preparation and characterization. For detailed explanation of liposome preparation, see Myhren et al ${ }^{34}$. The liposomes were stored at $4^{\circ} \mathrm{C}$ in light-proof containers, and used for experiments for up to 2 weeks after synthesis.

Three fluorescent monodispersed Fluoresbrite ${ }^{\circledR}$ Carboxylate Microspheres (PSNPs) (PS$\mathrm{COOH}, 2.6 \%$ solid (w/v) aqueous suspensions) were purchased from Polysciences, Inc.; Two bright blue (BB) carboxylate microspheres (particles size: $0.49 \mu \mathrm{m}$ and $0.997 \mu \mathrm{m}$ ) containing dyes (coumarin) with excitation maxima $360 \mathrm{~nm}$, and one yellow-green (YG) carboxylate microsphere (particles size: $0.19 \mu \mathrm{m}$ ) containing dyes (fluorescein) with excitation maxima $441 \mathrm{~nm}$. $\alpha$-Amino- $\omega$-methoxy-poly(ethylene glycol) 5000 (MPEG5k-NH${ }_{2}$ ) was synthesized according to a previous report ${ }^{35}$. The other chemicals, HOBt (1-hydroxybenzotrizole), EDAC (1-dimethylaminopropyl-ethylcarbodiimide hydrochloride), NHS ( $N$-hydroxysuccinimide), barium hydroxide solution $(0.05 \mathrm{M})$ were purchased from Sigma-Aldrich and used without further purification, unless otherwise stated.

For the "brush-like" immobilization of the MPEG5000- $\mathrm{NH}_{2}$ on the surface of carboxylate microspheres, we adapted a procedure from a previous report by using EDAC in the presence of HOBt in an aqueous solution at $4^{\circ} \mathrm{C}$ (Scheme 1) ${ }^{36,37}$. The larger PEGylated particles $(0.49 \mu \mathrm{m}$ and $0.997 \mu \mathrm{m})$ were purified by centrifugation at $10000 \mathrm{~g}$ for $10 \mathrm{~min}$ at RT, washed once with $0.01 \mathrm{M} \mathrm{HCl}$ and three times with PBS-buffered solution (pH 7.4) via re-dispersion and centrifugation. Finally, the particles were re-suspended in PBS $(0.044 \mathrm{wt} \%$ for $0.997 \mu \mathrm{m}$ and $0.344 \mathrm{wt} \%$ for $0.49 \mu \mathrm{m}$ PEGylation particles) and stored at $4^{\circ} \mathrm{C}$ until use. The smaller PEGylated NPs $(0.19 \mu \mathrm{m})$ were purified by dialysis, first against distilled water and then against PBS ( $\mathrm{pH} 7.4)$ at $4^{\circ} \mathrm{C}$ for 3 weeks using a dialysis membrane of regenerated cellulose with a molecular weight cut-off of 8000 . Finally, the suspension in PBS was stored at $4^{\circ} \mathrm{C}$ (the concentration: $0.443 \mathrm{wt} \%$ for $0.19 \mu \mathrm{m}$ PEGylated NPs) were determined by using UV-Vis photometer (the absorbance of the maximum peak vs particles concentration according to the Beer-Lambert law). 
Fish care and treatment. The ZF line AB (wt) was used for the following experiments: quantification of growth of human cancer cells, to study liposome accumulation in tumor-like structures, to analyze NPs circulation time and endothelium affinity. The ZF line $\operatorname{Tg}(f l i 1: E G F P) y 1$ was used to study the relation between ZF vasculature and injected human cancer cells, and to confirm that endothelium was the tissue to which PSNPs adhered. The ZF line Tg(mpeg1:mCherry) ${ }^{\text {UMSF001 }}$ was used to study in vivo macrophage uptake of NPs. Embryos were kept in standard embryo water containing $0.003 \%$ phenylthiourea (Aldrich) in Petri dishes at $28.5^{\circ} \mathrm{C}$. Embryos injected with human cancer cells were kept at $35^{\circ} \mathrm{C}$ and no adverse effects on their development were observed. The experiments were conducted in agreement with the provisions enforced by the Norwegian national animal research authority (NARA).

Cancer cell lines. The human metastatic melanoma cell line Melmet 5 was established from a lymph node biopsy of a metastatic melanoma patient at the department of Tumor Biology, The Norwegian Radium Hospital, as described previously ${ }^{38}$. Melmet 5 were maintained in culture in RPMI1640 medium (Lonza) completed with 10\% FBS (Saveen \& Werner) and $2 \%$ penicillin-streptomycin (Lonza). Melmet 5 was transduced and stably expresses a dsRed fluorescent marker for visualization. The commercially available human cell line HEK293 was maintained in culture in DMEM (Lonza) completed with $10 \%$ fetal bovine serum and $2 \%$ penicillin-streptomycin (Lonza). HEK293 (ATCC) was transduced and stably expresses a mCherry fluorescent marker for visualization. Both cell lines were incubated at $37^{\circ} \mathrm{C}, 5 \%$ $\mathrm{CO}_{2}$. The growth medium was changed every third day and cells were passaged following standard protocols prior to reaching confluence. When passaged or prepared for ZF injections Versene (Life Technologies) rather than trypsin were used to preserve the molecular profile on the cell membrane.

\section{In vitro assay for macrophage nanoparticle uptake. The PSNP (Polysciences Inc.)} solutions were prepared to get 100 multiplicity of infection (MOI) and 20 MOI. They were sonicated for 10 min before dilution. RAW macrophages were seeded in small individual dishes compatible with confocal imaging in RPMI1640 medium and left overnight for adhesion. Next morning, the PSNPs were mixed in RPMI1640 in a concentration of $2 \times 10^{8} / \mathrm{ml}$. Cell medium containing PSNPs was added to the cell dishes and incubated for $4 \mathrm{~h}$. The cells were subsequently washed 3 times with PBS to remove free PSNPs. Next, fresh medium was 
added before confocal imaging was performed. For liposome uptake experiments cells were seeded in the same way. The next morning a $1 \%$ liposomes solution was prepared in PBS and the PBS/liposome solution was incubated with the RAW macrophages for 10 minutes. The cells were washed and imaged as described for PSNPs.

Flow cytometry analysis: For flow cytometry analysis RAW cells were seeded at $1 \times 10^{6}$ cells per well in a 12 well dish in $1 \mathrm{~mL}$ medium and left for $4 \mathrm{~h}$ to allow adhesion. The NoPEG and PEG PSNP suspensions were added to the cells and mixed gently by swirling and incubated for $4 \mathrm{~h}$. Liposomes were added to RAW cells in PBS and incubated for $10 \mathrm{~min}$. Then cells were washed twice with ice cold DPBS without $\mathrm{Mg}^{2+}$ and $\mathrm{Ca}^{2+}$ before incubation in DPBS without $\mathrm{Mg}^{2+}$ and $\mathrm{Ca}^{2+}$ in the fridge for $10 \mathrm{~min}$. Subsequently, cells were scraped off and collected in the bottom of the dish before they were washed 3 times with ice cold DPBS without $\mathrm{Mg}^{2+}$ and $\mathrm{Ca}^{2+}$. Cells were kept on ice until the flow cytometry analysis. Analysis was performed using a FACSCalibur (BD Bioscience, New Jersey, USA) and Flowing Software 2.5.1. (Turku Centre of Biotochnology, University of Turku, Finland).

Cell debris and dead cells were excluded from analysis based on their forward and side scatter characteristics and at least 10000 viable cells were analyzed in each group.

ZF injections. Embryos were injected using a glass needle (Harvard apparatus) controlled with a Narishige MN-153 micromanipulator connected to an Eppendorf FemtoJet express. Microscopic visualization of the fish during injections was facilitated by a stereomicroscope Leica DFC365FX with a 1.0X Planapo lens.

Cancer cell injections: Cancer cells were grown in a T25 flask and harvested as described in the cell line section when reaching about $85 \%$ confluence. The cell suspension was centrifuged in a $15 \mathrm{ml}$ Falcon tube, washed once with PBS without re-suspending the pellet. PBS was removed until the pellet was only partially covered and re-suspended in the small remaining PBS. In order to establish the number of cells to be engrafted test injections were done in a drop of water on the lid of a petri dish. The injection pressure or injection time was adjusted to obtain the desired number of cells per injection. Two dpf embryos were anesthetized with tricaine as described in Gao et al. ${ }^{39}$ and 200-300 cancer cells were injected in the lower part of Duct of Cuvier ${ }^{7}$ (see Figure 1a). 24 h post injection embryos were screened for tumor-like structures in the tail. 
Nanoparticle injections: To study nanoparticle behavior in ZF embryos 2 dpf embryos were anesthetized as described above. A glass needle was prepared so that the tip was narrower than the posterior cardinal vein. The injection site for NPs is marked in Figure 1A.

Approximately $3 \mathrm{nl}$ of nanoparticle suspension was injected.

Accumulation of NPs in tumor-like structures: To study the potential for accumulation of NPs in the tumor-like structures in the tail of ZF embryos, two dpf embryos were injected with cancer cells as described above. Tumor-like structures were allowed to grow for two days and at four dpf, embryos with tumor-like structures in the tail and normal blood flow were injected with NPs. Embryos were anesthetized and inspected for potential accumulation of NPs in the tumor-like structures, using the Leica stereomicroscope, 2-5 h post injection of NPs.

ZF imaging. A Leica DFC365FX stereomicroscope with a 1.0X Planapo lens was used for quantification of growth of the fluorescent tumor-like structures in ZF embryos. It was also used for imaging of fluorescent NPs in ZF embryos and acquisition of time lapse videos of circulating NPs in ZF embryos. Prior to imaging ZF embryos were anesthetized by adding tricaine to embryo water. Upon imaging embryos were placed on a petri dish on a polymerized $1.5 \%$ agarose bed with just enough embryo water to avoid drying the embryo. All time lapse videos in supplementary data are shown at 7 frames per second.

An Olympus FluoView 1000 upright BX61WI confocal microscope was used for high-resolution microscopic imaging. Prior to imaging embryos were anesthetized in tricaine (Finquel, Argent Laboratories) as described in Gao et al. ${ }^{39}$ Subsequently, they were placed in a small dish with a glass bottom filled with low melting point agarose. Once the agarose polymerized, embryo water containing tricaine was added. We used a 40x water objective in Figure 1 and a 60x water objective in Figure 5 and 6. In Supplementary Figure 1 the blue dye Dextran (MW 10 000) was used. 3D view PlugIn in Fiji computer software was used in Figure $6 \mathrm{E}$ and F. The laser lines for confocal fluorescence imaging used were 405 (blue), 488 (green), 543 (red).

Fluorescent Pixel Count (FPC). The FPC was used to evaluate growth of injected cancer cells in the ZF embryos. The ZF was injected with cancer cells 2 dpf. The images were acquired at 2, 4 and 6 dpi using fluorescent stereomicroscopy with a Leica DFC365FX with a 1.0x Planapo lens. The tail region of the fish was imaged and analyzed with FPC using ImageJ software. The same zoom, gain and exposure times were used for all time points, 
although different settings were used for the two cancer cells lines. The fish were kept in individual wells in a 12-well plate during the experiments in order to track individual fish. The images were changed to 16-bit formats and pixel above lowest gray value of true signal was used to quantify the surface area of the tumor-like structure over the 3 time points.

Optical Tweezers Experiments. Cancer cells or macrophages were seeded out in individual $35 \mathrm{~mm}$ glass bottom dishes coated with poly-D-lysine (MatTek). The cell suspension was diluted to contain approximately 25000 cells $/ \mathrm{mL}$. $2 \mathrm{~mL}$ of this suspension was added to each dish. The cells had to be incubated at $37^{\circ} \mathrm{C}$ for at least 4 hours for them to adhere to the glass bottom dish before the experiment started. Before the experiment, the medium was removed, and the cells washed three times with PBS (Sigma). $2 \mathrm{~mL}$ of the solution containing the NPs were then added to the cells. Three different solutions with NPs were used for this experiment, PBS, RPMI-1640 (Sigma) or PBS with NPs incubated in mouse serum (Innovative Research Inc) for the macrophages or human serum (Innovative Research Inc) for the Melmet 5 cells.

For NPs that were incubated with either mouse serum, human serum or FBS (Saveen \& Werner) $0.000065 \mathrm{wt} \%$ of the NPs where incubated with $0.5 \mathrm{~mL}$ of the respective solution for $15 \mathrm{~min}$ at room temperature $\left(20-22^{\circ} \mathrm{C}\right)$ in a $1.5 \mathrm{~mL}$ Eppendorf centrifuge tube. Then the NP-serum solution was centrifuged for $15 \mathrm{~min}$ at $15.000 \mathrm{x}$ g. The supernatant was removed carefully, to avoid re-suspending the pellet. $0.5 \mathrm{~mL}$ of PBS was added, and the pellet resuspended. The solution was centrifuged for $15 \mathrm{~min}$ at $15.000 \mathrm{x} \mathrm{g}$ for $15 \mathrm{~min}$. This washing step was repeated one more time. After the last washing the supernatant was removed, $0.5 \mathrm{~mL}$ of PBS added and the pellet was re-suspended. $0.5 \mathrm{~mL}$ of the NP-solution was then diluted in 10 $\mathrm{mL}$ of PBS in a $50 \mathrm{~mL}$ tube, and sonicated for 5 min to make the solution monodisperse. Before adding the NPs that were incubated with the serum to the cells, the cells were washed three times with $3 \mathrm{~mL}$ of PBS to remove residual growth medium. After washing, $2 \mathrm{~mL}$ of the NP solution was added to the cells. For the samples where the NPs are not incubated with serum, we followed the same protocol, but only used PBS. After incubation of NPs in serum all analysis of NP adhesion to cells was carried out in PBS to study the effect of the bound serum proteins only.

SEM and TEM imaging. The liposomes were imaged using transmission electron microscopy (TEM) using a Philips CM100. A normal negative stain was applied using $2 \%$ uranyl acetate. The polystyrene NPs were imaged with scanning electron microscopy (SEM) 
using a Hitachi S-4800. The suspension of NPs was applied to the double-sided carbon tape and air-dried under a lamp for $30 \mathrm{~min}$. They were then coated with a $4 \mathrm{~nm}$ layer of platinum.

Statistics used. The statistics was done using Origin 9.1 software. For the in vitro optical tweezers and growth of the cancer cells after injection the Barnard's Exact test was used to determine $\mathrm{p}$-value, as the data were regarded as binary with regards to adhesion/no adhesion or growth/no-growth, respectively. Significance level is shown as $* * p<0.01,{ }^{*} p<0.05$.

The SE for the binary data was calculated using

$S E=\sqrt{\frac{\pi(1-\pi)}{n}}$, where $\pi=$ sample proportion of responders.

\section{Results and discussion}

Establishment of tumor-like structures in zebrafish embryos from injected human cancer cells. The zebrafish embryo is an established and accepted model for human cancer ${ }^{40}$. Our starting point was to use cancer cells known to grow tumors in mice and inject them into zebrafish embryos. These tumors would then allow in vivo testing of nanoparticles in a vertebrate model for human cancer.

Fluorescently labeled human cancer cells (200-300 cells, see Materials and Methods) were injected into the lower part of the Duct of Cuvier of ZF embryos 2 days post-fertilization (dpf) after which the dissemination of cancer cells via the vasculature to the tail tissue could be monitored by microscopy (Figure 1A). Embryos injected with human cancer cells were kept at $35^{\circ} \mathrm{C}$ as a compromise between the optimal temperatures for $\mathrm{ZF}$ embryos $\left(28^{\circ} \mathrm{C}\right)$ and human cells $\left(37^{\circ} \mathrm{C}\right)$. The human melanoma cell line Melmet 5 was first chosen because of the known capacity of these cells to establish solid tumors in mice ${ }^{38,41}$. Injected Melmet 5 cells extravasated from the embryo blood vessels within the first $24 \mathrm{~h}$ post injection. In the $\mathrm{ZF}$ embryos this cell line established both single and multiple tumor-like structures in the tail (Figure 1B). Using the transgenic ZF line $\operatorname{Tg}(f l i 1 a: E G F P)^{y 1}$, which has a GFP reporter gene expressed specifically in the endothelial cells ${ }^{42}$, resulting in a green fluorescent vasculature, we could observe the cancer cell location relative to the blood vessels. At the site of extravasation and growth of the tumor-like structure the Melmet 5 cells generated "pockets" in between blood vessels as they pushed the vasculature aside (Figure $1 \mathrm{C}-\mathrm{D}$ ). The blood flow was not observed to be affected by the presence of the tumor-like structure and no endothelial cells were seen to migrate into the tumor mass. 
The human embryonic kidney cells (HEK293) were also tested due to their tumorigenicity and ability to establish solid tumors in mice ${ }^{43,44}$. For these cells, extravasation from the embryo blood vessels was also observed within the first $24 \mathrm{~h}$. A striking characteristic of the HEK 293 cells was the generation of a single, prominent tumor-like structure in the tail of the embryo (Figure 1E). The relative location of the HEK293 tumorlike structure to the vasculature was different from the Melmet 5 phenotype, as it was peripheral to the vasculature rather than in between the blood vessels (Figure 1F-G). Also here, the blood flow was unaffected and no endothelial cells migrated into the tumor-like structure.

Quantifying the growth of the tumor-like structures every second day over a period of six days post-injection (Figure $1 \mathrm{H}$ ) showed that extravasated Melmet 5 cells had an average growth in volume of $84 \%$ from 2 days post injection (dpi) to $6 \mathrm{dpi}$, with variations among the individuals ranging from $13 \%$ decrease in size to a $162 \%$ increase in size. The HEK293 cells had a lower average growth (34\%), but a much higher degree of variation between embryos from 2 dpi to 6 dpi ranging from a $97 \%$ decrease in size to a $250 \%$ increase in size. Thus, Melmet 5 cells displayed a more consistent potential for sustained growth in the ZF embryo than the HEK293 cells.

The results collectively demonstrate the ability of ZF embryos to support cell survival of our injected human cancer cell lines, and even expansion of the tumor-like structures. These experiments set the stage for using the ZF embryo as a system for monitoring NPs in a dynamic in vivo vertebrate model for human cancer.

NPs without PEG have short circulation times in vivo. NPs without polyethylene glycol (PEG) coating are known to have short circulation times in vivo as they are more prone to clearance from circulation by macrophages ${ }^{45}$. The transparency of the ZF embryo model offers the possibility of fast, yet detailed in vivo investigation and imaging of the distribution of NPs throughout the organism ${ }^{29}$. By visual inspection using stereomicroscopy, we evaluated the circulation times and biodistribution of both polystyrene nanoparticles (PSNP) and liposomes without PEG (NoPEG) in 2 dpf embryos. We chose to work with these PSNPs as they have a uniform size and their carboxylated surface makes surface modification easy. The liposomes were included as this type of NPs are already used for therapeutic purposes in the clinic ${ }^{46}$.

In order to study biodistribution and circulation abilities of PSNPs we injected a blue fluorescent version of NoPEG PSNPs $(1000 \mathrm{~nm})$ into the circulation of $2 \mathrm{dpf}$ embryos of the 
transgenic fish line $\operatorname{Tg}(f l i l a: E G F P)^{y 1}$. This particular transgenic ZF line has green fluorescent vasculature and its role in the presence of PSNPs can be established. Using stereomicroscopy, it was evident that NoPEG PSNPs stopped circulating minutes after injection. They seemed to have a high affinity for the endothelium (Figure 2A), thereby hindering further circulation in the bloodstream.

With the aim to quantify circulation times, green fluorescent $200 \mathrm{~nm}$ NoPEG PSNPs (Table 1), having the same surface characteristics as the $1000 \mathrm{~nm}$ NPs, were injected into wild type ZF embryos having no fluorescence in the vasculature. Twenty seconds post injection the PSNPs circulated (Figure 2B, asterisk) but a fraction had already adhered prominently to the endothelium, as evident by intense green immobile dots (Figure 2B, red arrows, Supplementary video 1). By 140 seconds post injection there were relatively low levels of NoPEG PSNPs left in the circulation (Figure 2C, white asterisk, Supplementary Video 2), while there was increasing adhesion to the endothelium. The NoPEG PSNPs did not discriminate between the different blood vessels and adhered in comparable amounts to the caudal artery (Figure 2C, yellow asterisk), caudal vein (Figure 2C, red asterisk) and the dorsal longitudinal anastomotic vessel (DLAV) (Figure 2C, white arrow). The intersegmental vessels (ISV) are visible due to circulating NoPEG PSNPs, showing that they did not adhere to these narrow blood vessels (Figure 2C, yellow arrow).

Twenty minutes post injection there were no circulating NoPEG PSNPs due to their high affinity for the endothelium throughout the embryo. For example, individual endothelial cells could be observed in the caudal vein as a speckled pattern along the vasculature to which the NoPEG PSNPs had adhered (Figure 2D, green). The high affinity of the PSNPs for the endothelium appeared to be associated with toxicity as all the embryos died within $24 \mathrm{~h}$.

Analysis of the circulation time of green fluorescent NoPEG liposomes (average diameter $200 \mathrm{~nm}$, Table 1) were also performed. Liposomes were injected into the circulation of wild type embryos and shortly after injection the liposomes circulated through all blood vessels and consequently a full representation of the vasculature was visible as a green fluorescent signal (Figure 2E), giving it a similar appearance to the $\operatorname{Tg}\left(\right.$ flila:EGFP) $^{\boldsymbol{y} \boldsymbol{l}}$ fish. The circulation time of the NoPEG liposomes was several hours, significantly longer than NoPEG PSNPs. Infrequent events of random adhesion to the endothelium could be observed (Figure 2E, arrow) but liposome batches used within two weeks from their production did not adhere to the endothelium. Injecting the same liposomes into embryos from the transgenic $\mathrm{ZF}$ line $\operatorname{Tg}$ (mpeg1:mCherry) ${ }^{U M S F 001} 47$ with red fluorescent macrophages enabled us to study their role in clearance of liposomes from circulation. Inspection of embryos $20 \mathrm{~h}$ post-injection 
showed already a total clearance of liposomes from the circulation. From the injected mpeg cherry embryos it could be concluded that macrophages had cleared the liposomes from the circulation, as multiple yellow dots were visible in the tail, corresponding to the red macrophages filled with green liposomes (Figure 2F, arrows). Importantly, the liposomes did not adhere to the endothelium and showed no toxicity to the ZF embryos, in stark contrast to the NoPEG PSNPs.

PEG coated NPs display stealth properties in vitro. The paradigm in the NP field is that PEG adds stealth properties to NPs. The prevailing theory to explain this phenomenon is that this process prevents opsonization by plasma proteins, and thereby macrophage uptake, resulting in prolonged circulation time ${ }^{5,48-50}$. To investigate how PEG-coating of NPs affects their interaction with different cell types, we performed incubation studies with cells in vitro. For this we chose the mouse macrophage RAW cell line which display classic macrophage behavior regarding uptake of foreign particles ${ }^{51,52}$. We used $200 \mathrm{~nm}$ commercial PSNPs and liposomes, shown by electron microscopy in Fig 3A. Green fluorescent $200 \mathrm{~nm}$ NoPEG or PEG PSNP were first added to the cell medium of RAW cell cultures and incubated for 4 hours. After washing away unbound NPs, the cells were imaged by confocal microscopy. The images show that NoPEG PSNPs were taken up in high amounts, as the cells had acquired bright fluorescence from the NPs (Figure 3B-1). In contrast, the PEGylated PSNPs were taken up by the cells at much lower levels (Figure 3B-2). To quantify the levels taken up by macrophages we performed flow cytometry showing a two-fold increase in uptake of NoPEG PSNPs compared to PEG PSNPs (Figure 3C).

The PEG effect was also studied using $200 \mathrm{~nm}$ liposomes (Table 1, Figure 3D). Due to heavy aggregation of liposomes in the presence of serum in the cell medium this experiment had to be carried out in PBS. Liposomes in PBS were added to the RAW cells and incubated for only 10 minutes as titration experiments showed rapid influx of liposomes in RAW cells. Confocal analysis indicated that NoPEG (Figure 3D-1) and PEG liposomes (Figure 3D-2) were taken up in similar amounts by the cells. The rapid uptake of liposomes into macrophages resulted in a very short time window to study the effect of PEG and excluded them from reliable flow cytometry analysis. Collectively, these results show that PEGylation of PSNPs lowers their uptake by macrophages, a favorable result in the context of one of the biggest challenges for obtaining long circulating NPs. 
Quantification of the effect of PEGylation of NPs using optical tweezers. The above data showed that PEG reduces the uptake of PSNPs by macrophages. In order to analyze the interactions between cells and PSNPs in more detail we carried out controlled micromanipulation using optical tweezers (OT). The OT makes it possible to quantify the interactions of individual PSNPs with a single cell under different conditions, in real time. The small size of the liposomes excluded them for this type of study.

In these experiments there are three possible outcomes: 1) the OT is not strong enough to remove the NP from the cell, 2) the NP and cell can be moved apart but remain connected through a tether ${ }^{53}$ or 3 ) the particle and cell can be moved apart, since no sufficiently strong adhesion has been made. Here, we classified the tethered particle as 'adhered'. The adhesion percentage was then defined as the number of adhered particles/ total number of experimental attempts at adhesion $\mathrm{x} 100 \%$.

First, we tested whether the size of the NoPEG PSNPs was proportional to the degree of adhesion. Two sizes of PSNPs with a diameter of $1000 \mathrm{~nm}$ and $500 \mathrm{~nm}$ (Table 1) were used. We found that the $1000 \mathrm{~nm}$ NoPEG PSNP displayed a significantly higher binding affinity than the $500 \mathrm{~nm}$ NoPEG PSNPs (Figure 4A). NoPEG $500 \mathrm{~nm}$ PSNPs interacted strongly with RAW macrophages (85\%) but compared to the $1000 \mathrm{~nm}$ particles they had a $10 \%$ reduction in the level of adhesion.

We next investigated whether PEGylation of the PSNPs would result in a lower adhesion to macrophages, as was expected based on our microscopy and flow cytometry experiments. Figure 4B shows snapshots of movies recorded of $1000 \mathrm{~nm}$ PSNPs, with or without PEG, pushed against a RAW macrophage. The striking difference is that the NoPEG PSNPs already adhered to the macrophage surface within seconds after the first contact and the macrophage started to engulf it within the first minute (Figure 4B, left panel, arrow, Supplementary Video 3). In contrast, a PEG PSNP did not stimulate such a response even after making multiple, transient, forced contacts with the RAW macrophage (Figure 4B, right panel, arrow, Supplementary Video 4).

When quantifying the degree of adhesion and comparing NoPEG vs PEG PSNPs we indeed found that PEG added a measurable stealth effect to PSNPs in vitro. Coating the 1000 nm PSNP with PEG significantly decreased their adhesion to macrophages (Figure 4C). A similar decrease in adhesion to macrophages was observed when coating $500 \mathrm{~nm}$ PSNPs with PEG. By comparing the degree of adhesion for the $1000 \mathrm{~nm}$ and $500 \mathrm{~nm}$ PSNPs with PEG coating, the relevance of size for adhesion was eliminated as both the $1000 \mathrm{~nm}$ and $500 \mathrm{~nm}$ showed similar affinity for the macrophages (Figure 4C). Importantly, compared to the 
NoPEG PSNPs the degree of adhesion of the PEG PSNPs was reduced by 60-70\% (Figure $4 \mathrm{~A})$.

It is widely believed that the main effect of NP PEGylation in vivo is to reduce the binding of serum proteins and the process of opsonization. In the absence of PEG, serum proteins such as IgG and complement bind to the NPs and allow binding to receptors on the surface of phagocytic cells, such as macrophages ${ }^{54-56}$. To address the potential role of opsonization by serum proteins we pre-incubated one set of $1000 \mathrm{~nm}$ PSNPs with undiluted mouse serum (for mouse macrophages). As controls, two other sets of PSNPs were incubated in either undiluted fetal bovine serum or phosphate-buffered saline (PBS) solution. The further examination of the interactions between NPs and cells was carried out in PBS. All three sets of NoPEG PSNPs were found to have high levels of adhesion to macrophages (above 75\%). Conversely, the level of adhesion for PEG PSNPs was below 5\% for all three sets (Figure 4D). This shows that while PEG lowers the interaction between PSNPs and RAW macrophages, serum had no additional effect on the interactions between NoPEG PSNPs and macrophages.

In a subsequent set of experiments, we determined the adhesion of $1000 \mathrm{~nm}$ PSNPs to the human Melmet 5 cancer cells. Therefore, one set of PSNPs was pre-incubated in undiluted human serum (HS). NoPEG PSNPs adhered much weaker to the Melmet 5 cells compared to RAW macrophages and PEGylation further lowered the interaction between PSNPs and Melmet 5 cells. NoPEG PSNP had a degree of interaction above $65 \%$ while the PEG PSNPs interaction with Melmet 5 cells were practically eliminated (Figure 4E). Note that NoPEG PSNPs pre-incubated in PBS adhered more frequently to Melmet 5 cells than NoPEG PSNPs pre-incubated with FBS and HS.

The use of optical tweezers to quantify the effects of surface coating and other parameters of NPs is a novel and promising strategy. Optical tweezers allow the interactions between NPs and cells to be analyzed in a controlled and detailed manner. By trapping single NPs and bringing them in contact with cells, interaction times and adhesion forces were quantified. We found that the level of adhesion of NP to macrophages depends on the particle size and that PEG coating eliminates this effect. In addition, using this high precision technique we investigated how the presence of serum proteins on the surface of PSNPs influenced their interactions with RAW macrophages and whether PEG had an effect in this system. The classical idea is that PEG prevents opsonization; marking of foreign objects in the blood stream for recognition and uptake by macrophages ${ }^{57}$. Implied in this idea is the fact that in the absence of PEG these serum opsonins are the main factors responsible for 
macrophage uptake. However, in our experiments we failed to see any increased adhesion of NoPEG PSNPs to macrophages that were incubated with serum. Nevertheless, our results with optical tweezers show that the NoPEG PSNPs show high affinity binding to the macrophages in the absence of serum. This agrees with the data of Diakonova et. al who demonstrated that efficient internalization of latex beads by macrophages occurs in serum-free conditions ${ }^{58}$. Even though it is difficult to define the responsible molecular players scavenger receptors have been suggested to be responsible for the non-specific, high-affinity binding of particles to macrophages ${ }^{59}$.

PEGylation of PSNPs significantly reduced binding to macrophages. However, for NPs in cancer therapy an additional challenge is to stimulate selective uptake by cancer cells while avoiding macrophage uptake ${ }^{60}$. Therefore, we also investigated the interactions of PSNPs, with and without PEG, in the presence and absence of serum, with the human Melmet 5 cancer cells. The PSNPs without PEG or serum interacted less efficiently with Melmet 5 cells than to macrophages. The addition of PEG completely blocked all measurable binding of PSNPs to these cancer cells, as previously shown for PEG NPs ${ }^{60}$. However, with HEK293 cells PEG PSNPs bound more than NoPEG PSNPs (data not shown). The effect of serum was also unpredictable. The data imply that serum reduces the ability of the NoPEG PSNPs to bind passively to Melmet 5 cells. The addition of serum had no effect on the inability of the PEG PSNPs to bind to the Melmet 5 cells. Therefore, our results with macrophages reveal a predictable stealth effect of PEG on PSNP binding and no significant effect of serum in this system. In contrast, it is more difficult to make general conclusions about serum or PEG in the binding of PSNPs to cancer cells.

Although more detailed studies are needed to make more definitive conclusions, the simplest interpretation of our data in RAW macrophages is that in the absence of PEG on the surface of the PSNP, the particle bind directly to macrophage surface receptors. The PEG molecule directly, rather than indirectly via serum proteins, lowers the interactions between the PSNPs and macrophage surface receptors. By using the optical tweezer to study NP-cell interactions we demonstrate the potential of this method to generate detailed knowledge about how cells interact with NPs with different characteristics.

PEGylation of NPs prolongs in vivo circulation time. Having demonstrated a clear stealth effect provided by PEG in vitro we next investigated whether this effect could also be observed in the zebrafish, resulting in prolonged NP circulation time in vivo. As described 
above, NoPEG PSNPs displayed undesirable properties in the ZF embryo, such as short circulation times and a high general affinity for the endothelium as they did not discriminate between the different blood vessels in the tail (Figure 2C). We therefore investigated whether PEG could improve the quality of the PSNPs regarding these undesirable properties.

Green fluorescent $200 \mathrm{~nm}$ PEG PSNPs (Table 1) were injected in the posterior cardinal vein of $2 \mathrm{dpf}$ wt embryos (Figure 1A). 20 seconds post injection these particles were circulating (Figure 5A, white asterisk, supplementary video 5) and displayed relative low affinity for the endothelium. Further, they only adhered to the small vessels (Figure 5A, red arrow) in between the caudal artery (Figure 5A, yellow asterisk) and caudal vein (Figure 5A, red asterisk). 140 seconds post injection a relatively high amount of PEG PSNPs were still in circulation (Figure 5B, white asterisk). The PEG PSNPs discriminated between the different blood vessels, as vessels with strong blood flow did not attract PEG PSNPs; they did not adhere to the narrow DLAV vessels (Figure 5B, white arrow), the caudal artery (Figure 5B, yellow asterisk) nor the caudal vein (Figure 5B, red asterisk). Thus, the affinity of the PEG PSNPs was for the most part directed towards the smaller blood vessels (Figure 5B, red arrow) with natural, weaker blood flow (Supplementary video 6). The maximum detectable circulation time for PEG PSNPs was about 60 minutes, as evident when the NPs were injected into the $\operatorname{Tg}$ (mpeg1:mCherry) ${ }^{U M S F 001}$ zebrafish line. At no time points did the green PEG PSNPs co-localize with the red fluorescent macrophages (Figure 5C), suggesting that they are adhered to the endothelium as the circulation time appeared to be too short for the macrophages to be able to take them up.

We next carried out the same experiment with liposomes. The NoPEG version of the liposomes displayed circulation abilities, at first glance compatible with good stealth properties, as they did not attach to the endothelium. However, they were cleared from the circulation long before $20 \mathrm{~h}$ post injection by macrophages. Therefore we investigated whether the presence of PEG could delay this process. The addition of PEG to liposomes showed a distinct improvement since they stayed in circulation 24 hours post injection, as observed by the completely visible vasculature in the tail (Figure 5D, Supplementary Video 7). Even though the majority of the PEG liposomes were still circulating it was noteworthy that macrophages had begun to clear PEG liposomes from the circulation, as shown by using the ZF line with red fluorescent macrophages (Figure 5D, yellow, arrow). By $46 \mathrm{~h}$ post injection even more PEG liposomes were taken up by the macrophages (Figure 5E, green dots, arrows, Supplementary Video 8), but a considerable number of liposomes were still circulating. Inspection of the embryo by stereomicroscopy $70 \mathrm{~h}$ post injection showed a total clearance of 
PEG liposomes from the blood circulation (Supplementary Video 9), since at this point they were all taken up by macrophages (Figure 5F, arrow). No liposomes were observed to adhere to the endothelium and importantly, the liposomes were evidently not toxic, as the embryos survived with liposomes present in the circulation for at least $50 \mathrm{~h}$. The PEG molecules need to have a specific morphology and be oriented outwards from the NP surface to be effective. This morphology is known to change over time and become non-functional, which could explain the eventual uptake of PEG liposomes by macrophages ${ }^{61}$.

Using fluorescent polystyrene nanoparticles and liposomes, we demonstrate that the ZF embryo model makes it possible to follow the NPs from the time of injection up to the point when they are removed from circulation. We could identify two undesirable localization sites in the fish where NPs accumulated: the endothelium and the macrophages. The ability of endothelial cells to bind and to take up NPs has not been studied much in the field of NP therapy against cancer, even though it has been shown in one publication that the vasculature is indeed able to clear foreign objects from circulation in the zebrafish ${ }^{62}$. The association of NPs with endothelial cells in vivo has been observed in mice ${ }^{21}$, however methods available to routinely visualize NPs in mice may have have precluded identification of their potential binding to blood vessels ${ }^{17-19,33,63-66}$. Earlier studies have described binding and uptake of latex particles to sinusoidal endothelial cells after perfusion of rat liver ${ }^{20}$. Thus, adhesion of NPs to the endothelium seems therefore to be a poorly appreciated phenomenon. Drugcontaining NPs that adhere in a non-specific manner to the vasculature will likely have a high probability for toxic side-effects and this interaction must presumably be kept to a minimum. Tumor vasculature is considered a valid target in cancer therapy ${ }^{67}$ and it is possible to target a sub-compartment of the vasculature with NPs ${ }^{68}$. In vitro a considerable uptake of NPs by endothelial cells has been demonstrated and PEGylation of NPs lowers endothelial cell uptake ${ }^{69}$. This is in agreement with our results, which show that PEGylated NPs circulates longer than NPs without PEG and PEGylation was associated with a marked reduction in the endothelial binding of NPs. This shows that the ZF embryo is a highly suitable in vivo model to quickly screen a panel of NPs in the search for candidates with desirable characteristics.

In contrast to endothelium-NP interactions, the undesirable phenomenon of macrophage uptake of NPs from the circulation is well-characterized ${ }^{70,71}$. In mice, NP injections are routinely followed by killing the animal, removal of body fluid at the site of injection to harvest macrophages, centrifugation and filtering the re-suspended cell suspension before flow cytometry analysis ${ }^{72}$. In contrast, in the ZF embryo model it is straightforward to monitor macrophage uptake of NPs directly by imaging techniques of live embryos, 
especially when combined with the transgenic fish lines with fluorescently labeled macrophages.

\section{PEGylated liposomes accumulate passively and specifically to the region of human} tumor-like structures in ZF embryos. The observed long circulation time of PEG liposomes makes them a promising candidate for testing their ability for passive targeting to the human tumor-like structures. Given that the NoPEG PSNPs were cleared relatively fast from the circulation we did not investigate their possible accumulation in the tumors.

Melmet 5 or HEK293 cells were injected into 2 dpf wild type embryos and tumor-like structures were allowed to develop for two days. Embryos that fulfilled the two selection criteria of having tumor masses in the tail and a normal blood flow throughout the whole embryo were subsequently injected with PEG liposomes at 4 dpf into the posterior cardinal vein (Supplementary Video 10). Strikingly, imaging of these embryos revealed a specific and rapid accumulation of liposomes into tumor-like structures of both cell lines. For the Melmet 5 cells liposomes accumulated specifically close to the sites of the tumor-like structure already at $2 \mathrm{~h}$ post injection. At this time-point, there were no liposomes taken up by macrophages or attached to the endothelium (Figure 6A). Some embryos having multiple tumor structures clearly showed the apparent specificity of the accumulation of liposomes to areas with cancer cells (Figure 6B, arrows, Supplementary Video 11). In Figure 6B, the tumor structures furthest to the right showed a pattern of liposomes adhering to the endothelium specifically in the area around cancer cells, opening up the possibility that Melmet 5 cells secrete factors that locally affect the vasculature.

Tumor-like structures comprised of HEK293 were also able to strongly and selectively accumulate PEG liposomes within the tumor mass after $5 \mathrm{~h}$ (Figure 6C). However, liposomes seemed to accumulate more around the HEK293 tumor structures. This was in contrast to Melmet 5 structures, where liposomes seemed to have a tighter association with the tumorlike structure.

A control embryo not injected with cancer cells shows the distribution of the PEG liposomes after $6 \mathrm{~h}$ of circulation (Figure 6D). Some green "hotspots" can be observed (Figure 6D, arrows), that represent macrophages starting to clear liposomes from the circulation. Notably, there is no accumulation of liposomes elsewhere, in the absence of cancer cells.

To verify the difference in the profile of liposome accumulation in Melmet 5 and HEK293 tumor-like structures observed in Figure 6A and 6C, respectively, we performed 
confocal microscopy to study the pattern in more detail. Two embryos with tumor-like structures were examined by acquisition of confocal stacks. A 3D-view of the Melmet 5 tumors showed a tight association between liposomes and the Melmet 5 cells (Figure 6E, Supplementary Video 12). Some liposomes seem to have penetrated into the tumor mass (Figure 6E, arrow) but the majority were located at the periphery. It is not clear if the liposomes were taken up by the Melmet 5 cells or whether they were located on the surface of the cancer cells. The HEK293 tumor-like structure, in contrast, showed a looser association with the liposomes (Figure 6F, Supplementary Video 13). Liposomes were located at the areas around the tumor-like structure but were not taken up by the cancer cells. This image could suggest that most liposomes are not yet fully out of circulation and are still attached to the vasculature, which is present both above and underneath the tumor-like structure.

To more closely study the mechanism behind accumulation of liposomes in tumors we injected blue fluorescent dextran into the circulation of $\operatorname{Tg}($ flil:EGFP)yl embryos with Melmet 5 or HEK293 tumor-like structures. Within the limited time frame that dextran stays restricted to the blood vessels (up to $30 \mathrm{mins}^{29}$ ) it did not passively leak into the tumor mass (Supplementary Figure 1). This suggests that liposome accumulation in the tumor-like structures outside the vasculature is not due to non-specific leakage out of the vasculature.

To our knowledge we are the first to image the accumulation of NPs to human tumorlike structures established in the ZF embryo model. No other animal model currently exists where NP circulation through tumor tissues can be monitored so easily over time. The accumulation of liposomes in the tumor masses was especially rapid and apparently selectively, in spite of the fact that our NPs did not contain molecules that could actively target the NPs to the tumor cells ${ }^{73}$. After only 2-5 h high levels of PEG liposomes accumulated selectively in the tissue where the Melmet 5 or the HEK293 tumor-like structures resided. A plausible explanation for the leakage into both types of tumor-like structures is that the tumor cells secrete growth factors that affect the integrity of the vasculature locally. HEK293 cells express VEGF 74,75 , the most potent inducer of angiogenesis, and could be responsible for loosening the junctions between endothelial cells ${ }^{76}$. Further, Melmet 5 cells activate in vitro HUVEC migration, tube formation and induce expression of pro-angiogenic growth factors ${ }^{77}$. This leads us to speculate that a local activation of endothelial cells in the ZF embryo may lead to a destabilized vasculature. Whether this effect corresponds to the well-known phenomenon of enhanced permeability and retention (EPR) effect described for mammalian systems remains to be determined ${ }^{78}$. The fact that we could not see leakage of dextran into tumor masses suggests that accumulation of 
liposomes outside the vasculature is a regulated process rather than just passive NP leakage out of the blood vessels. Nevertheless, two different cell lines, one cancer (Melmet 5) and one tumorigenic cell line (HEK) were able to stimulate accumulation of NPs in the close vicinity of tumors. The patterns of NP-accumulation for the two types of tumor-like structures were slightly different, suggesting different mechanisms. Thus, the zebrafish embryo model can be used to study the mechanism of NP-accumulation for a wide range of metastatic cancer cell lines.

\section{Conclusions}

Here we introduce the ZF embryo and optical tweezers as novel tools for testing novel NPs aimed for cancer therapy. We present a strategy that can be used to screen for novel anticancer NPs in order to identify leading candidates for subsequent testing in more conventional animal models such as mouse. Undesirable anti-cancer NP properties such as uptake by macrophages and attachment to endothelia are easily and rapidly identified and characterized in ZF embryos. Conversely, the system also allows desirable properties to be monitored, such as NP accumulation in tumor tissues. This in vivo model opens the way for future systematic studies of NPs in dynamic models of human cancer. This will greatly facilitate the search for the most effective materials and surface properties to make NPs for tumor targeting purposes. In this study, we chose PEG as a model molecule to add stealth properties to NPs as it has been extensively studied and its effects are well known. In accordance with results in the literature, we found that PEG lowers NP uptake by macrophages and increases NP circulation times; moreover, the zebrafish embryo model is sensitive enough to discriminate between PEG-coated and 'naked' NPs. This opens up for testing of more experimental surface coating of NPs in order to identify novel promising candidates for cancer therapy.

Additionally, we demonstrate desirable effects of PEG on NPs in vitro as macrophages do not adhere to PEG-coated NPs. Our optical tweezer experiments further provide detailed data regarding NP surface coating and how this affects interactions with macrophages and cancer cells. A stealth effect could further be observed in vivo as PEG coated NPs had longer circulation times and lower affinity for endothelium in ZF embryos. Finally, liposome NPs were shown to passively accumulate in vivo in tumor-like structures comprised of human cancer cells. 


\section{Acknowledgements}

We thank Ana Carolina Tavara for her invaluable support with zebrafish maintenance. We also received excellent support from the IBV light microscopy and EM imaging platforms at the IBV, University of Oslo. We thank Jean-Pierre Levraud and Graham Lieschke for the mpeg1:cherry fish and James Lorens for the fli1:EGFP fish. The project was generously supported by the Norwegian Cancer Society.

Conflict of interest: The authors declare no competing financial interest.

Supporting information available: Additional figures and videos as described in the text.

1. L. A. Torre, F. Bray, R. L. Siegel, J. Ferlay, J. Lortet-Tieulent and A. Jemal, CA: a cancer journal for clinicians, 2015, DOI: 10.3322/caac. 21262.

2. A. E. Kayl and C. A. Meyers, Current opinion in obstetrics \& gynecology, 2006, 18, 24-28.

3. D. Church, R. Kerr, E. Domingo, D. Rosmarin, C. Palles, K. Maskell, I. Tomlinson and D. Kerr, Nature reviews. Cancer, 2014, 14, 440-445.

4. T. Sun, Y. S. Zhang, B. Pang, D. C. Hyun, M. Yang and Y. Xia, Angewandte Chemie, 2014, 53, 12320-12364.

5. A. Z. Wang, R. Langer and O. C. Farokhzad, Annual review of medicine, 2012, 63, 185-198.

6. M. E. O'Brien, N. Wigler, M. Inbar, R. Rosso, E. Grischke, A. Santoro, R. Catane, D. G. Kieback, P. Tomczak, S. P. Ackland, F. Orlandi, L. Mellars, L. Alland, C. Tendler and C. B. C. S. Group, Annals of oncology : official journal of the European Society for Medical Oncology / ESMO, 2004, 15, 440-449.

7. S. He, G. E. Lamers, J. W. Beenakker, C. Cui, V. P. Ghotra, E. H. Danen, A. H. Meijer, H. P. Spaink and B. E. Snaar-Jagalska, The Journal of pathology, 2012, 227, 431-445.

8. Y. Teng, X. Xie, S. Walker, D. T. White, J. S. Mumm and J. K. Cowell, BMC Cancer, 2013, 13, 453.

9. J. F. Amatruda, J. L. Shepard, H. M. Stern and L. I. Zon, Cancer cell, 2002, 1, 229-231.

10. K. Howe, M. D. Clark, C. F. Torroja, J. Torrance, C. Berthelot, M. Muffato, J. E. Collins, S. Humphray, K. McLaren, L. Matthews, S. McLaren, I. Sealy, M. Caccamo, C. Churcher, C. Scott, J. C. Barrett, R. Koch, G. J. Rauch, S. White, W. Chow, B. Kilian, L. T. Quintais, J. A. Guerra- 
Assuncao, Y. Zhou, Y. Gu, J. Yen, J. H. Vogel, T. Eyre, S. Redmond, R. Banerjee, J. Chi, B. Fu, E. Langley, S. F. Maguire, G. K. Laird, D. Lloyd, E. Kenyon, S. Donaldson, H. Sehra, J. Almeida-King, J. Loveland, S. Trevanion, M. Jones, M. Quail, D. Willey, A. Hunt, J. Burton, S. Sims, K. McLay, B. Plumb, J. Davis, C. Clee, K. Oliver, R. Clark, C. Riddle, D. Elliot, G. Threadgold, G. Harden, D. Ware, S. Begum, B. Mortimore, G. Kerry, P. Heath, B. Phillimore, A. Tracey, N. Corby, M. Dunn, C. Johnson, J. Wood, S. Clark, S. Pelan, G. Griffiths, M. Smith, R. Glithero, P. Howden, N. Barker, C. Lloyd, C. Stevens, J. Harley, K. Holt, G. Panagiotidis, J. Lovell, H. Beasley, C. Henderson, D. Gordon, K. Auger, D. Wright, J. Collins, C. Raisen, L. Dyer, K. Leung, L. Robertson, K. Ambridge, D. Leongamornlert, S. McGuire, R. Gilderthorp, C. Griffiths, D. Manthravadi, S. Nichol, G. Barker, S. Whitehead, M. Kay, J. Brown, C. Murnane, E. Gray, M. Humphries, N. Sycamore, D. Barker, D. Saunders, J. Wallis, A. Babbage, S. Hammond, M. Mashreghi-Mohammadi, L. Barr, S. Martin, P. Wray, A. Ellington, N. Matthews, M. Ellwood, R. Woodmansey, G. Clark, J. Cooper, A. Tromans, D. Grafham, C. Skuce, R. Pandian, R. Andrews, E. Harrison, A. Kimberley, J. Garnett, N. Fosker, R. Hall, P. Garner, D. Kelly, C. Bird, S. Palmer, I. Gehring, A. Berger, C. M. Dooley, Z. Ersan-Urun, C. Eser, H. Geiger, M. Geisler, L. Karotki, A. Kirn, J. Konantz, M. Konantz, M. Oberlander, S. Rudolph-Geiger, M. Teucke, C. Lanz, G. Raddatz, K. Osoegawa, B. Zhu, A. Rapp, S. Widaa, C. Langford, F. Yang, S. C. Schuster, N. P. Carter, J. Harrow, Z. Ning, J. Herrero, S. M. Searle, A. Enright, R. Geisler, R. H. Plasterk, C. Lee, M. Westerfield, P. J. de Jong, L. I. Zon, J. H. Postlethwait, C. Nusslein-Volhard, T. J. Hubbard, H. Roest Crollius, J. Rogers and D. L. Stemple, Nature, 2013, 496, 498-503.

11. S. H. Lam, H. L. Chua, Z. Gong, T. J. Lam and Y. M. Sin, Dev Comp Immunol, 2004, 28, 9-28.

12. D. M. Tobin, R. C. May and R. T. Wheeler, PLoS pathogens, 2012, 8, e1002349.

13. X. J. Yang, W. Cui, A. Gu, C. Xu, S. C. Yu, T. T. Li, Y. H. Cui, X. Zhang and X. W. Bian, PloS one, 2013, 8, e61801.

14. M. Konantz, T. B. Balci, U. F. Hartwig, G. Dellaire, M. C. Andre, J. N. Berman and C. Lengerke, Ann N Y Acad Sci, 2012, 1266, 124-137.

15. L. I. Zon and R. T. Peterson, Nature reviews. Drug discovery, 2005, 4, 35-44.

16. R. Coradeghini, S. Gioria, C. P. García, P. Nativo, F. Franchini, D. Gilliland, J. Ponti and F. Rossi, Toxicology Letters, 2013, 217, 205-216.

17. A. K. Mohammad, L. K. Amayreh, J. M. Mazzara and J. J. Reineke, Pharmaceutical research, 2013, 30, 424-434.

18. H. A. Palko, J. Y. Fung and A. Y. Louie, Inhalation toxicology, 2010, 22, 657-688.

19. B. H. Simon, H. Y. Ando and P. K. Gupta, Journal of pharmaceutical sciences, 1995, 84, 12491253.

20. C. Dan and K. Wake, Experimental cell research, 1985, 158, 75-85.

21. S. M. Moghimi, A. C. Hunter and J. C. Murray, FASEB journal : official publication of the Federation of American Societies for Experimental Biology, 2005, 19, 311-330.

22. L. Rocco, M. Santonastaso, F. Mottola, D. Costagliola, T. Suero, S. Pacifico and V. Stingo, Ecotoxicology and environmental safety, 2015, 113, 223-230.

23. J. Gao, M. S. Sepulveda, C. Klinkhamer, A. Wei, Y. Gao and C. T. Mahapatra, Chemosphere, 2015, 119, 948-952.

24. Y. J. Wang, Z. Z. He, Y. W. Fang, Y. Xu, Y. N. Chen, G. Q. Wang, Y. Q. Yang, Z. Yang and Y. H. Li, International journal of ophthalmology, 2014, 7, 917-923.

25. D. S. Wagner, N. A. Delk, E. Y. Lukianova-Hleb, J. H. Hafner, M. C. Farach-Carson and D. O. Lapotko, Biomaterials, 2010, 31, 7567-7574.

26. C. Y. Gong, S. Y. Deng, Q. J. Wu, M. L. Xiang, X. W. Wei, L. Li, X. Gao, B. L. Wang, L. Sun, Y. S. Chen, Y. C. Li, L. Liu, Z. Y. Qian and Y. Q. Wei, Biomaterials, 2013, 34, 1413-1432.

27. Q. J. Wu, S. Y. Deng, L. Li, L. Sun, X. Yang, X. Y. Liu, L. Liu, Z. Y. Qian, Y. Q. Wei and C. Y. Gong, Nanoscale, 2013, 5, 12480-12493.

28. Q. J. Wu, G. Y. Li, S. Y. Deng, L. Ouyang, L. Li, L. Liu, N. Luo, X. R. Song, G. He, C. Y. Gong and Y. Q. Wei, Nanoscale, 2014, 6, 11940-11952. 
29. F. Fenaroli, D. Westmoreland, J. Benjaminsen, T. Kolstad, F. M. Skjeldal, A. H. Meijer, M. van der Vaart, L. Ulanova, N. Roos, B. Nystrom, J. Hildahl and G. Griffiths, Acs Nano, 2014, 8, 7014-7026.

30. R. Bazak, M. Houri, S. El Achy, S. Kamel and T. Refaat, Journal of cancer research and clinical oncology, 2014, DOI: 10.1007/s00432-014-1767-3.

31. P. L. Rodriguez, T. Harada, D. A. Christian, D. A. Pantano, R. K. Tsai and D. E. Discher, Science, 2013, 339, 971-975.

32. G. Lollo, P. Hervella, P. Calvo, P. Aviles, M. J. Guillen, M. Garcia-Fuentes, M. J. Alonso and D. Torres, International journal of pharmaceutics, 2015, 483, 212-219.

33. G. Pasut, D. Paolino, C. Celia, A. Mero, A. S. Joseph, J. Wolfram, D. Cosco, O. Schiavon, H. Shen and M. Fresta, Journal of controlled release : official journal of the Controlled Release Society, 2015, 199, 106-113.

34. L. Myhren, I. M. Nilssen, V. Nicolas, S. O. Doskeland, G. Barratt and L. Herfindal, European journal of pharmaceutics and biopharmaceutics : official journal of Arbeitsgemeinschaft fur Pharmazeutische Verfahrenstechnik e.V, 2014, 88, 186-193.

35. H. F. Xu, F. H. Meng and Z. Y. Zhong, J Mater Chem, 2009, 19, 4183-4190.

36. F. Meng, G. H. Engbers and J. Feijen, Journal of biomedical materials research. Part A, 2004, 70, 49-58.

37. F. Meng, G. H. Engbers, A. Gessner, R. H. Muller and J. Feijen, Journal of biomedical materials research. Part A, 2004, 70, 97-106.

38. L. Prasmickaite, N. Skrbo, H. K. Hoifodt, Z. Suo, O. Engebraten, H. P. Gullestad, S. Aamdal, O. Fodstad and G. M. Maelandsmo, Pigment Cell Melanoma Res, 2010, 23, 449-451.

39. L. Y. Gao and J. Manoranjan, Current protocols in microbiology, 2005, Chapter 10, Unit 10B 11.

40. S. Nicoli and M. Presta, Nat Protoc, 2007, 2, 2918-2923.

41. V. Nygaard, L. Prasmickaite, K. Vasiliauskaite, T. Clancy and E. Hovig, Oncoscience, 2014, 1, 82-94.

42. N. D. Lawson and B. M. Weinstein, Developmental biology, 2002, 248, 307-318.

43. G. Jin, H. I. Kawsar, S. A. Hirsch, C. Zeng, X. Jia, Z. M. Feng, S. K. Ghosh, Q. Y. Zheng, A. M. Zhou, T. M. McIntyre and A. Weinberg, Plos One, 2010, 5.

44. A. A. Stepanenko and V. V. Dmitrenko, Gene, 2015, DOI: 10.1016/j.gene.2015.05.065.

45. J. V. Jokerst, T. Lobovkina, R. N. Zare and S. S. Gambhir, Nanomedicine, 2011, 6, 715-728.

46. V. P. Torchilin, Nature reviews. Drug discovery, 2005, 4, 145-160.

47. A. Bernut, J. L. Herrmann, K. Kissa, J. F. Dubremetz, J. L. Gaillard, G. Lutfalla and L. Kremer, Proc Natl Acad Sci U S A, 2014, 111, E943-952.

48. A. Albanese, P. S. Tang and W. C. Chan, Annual review of biomedical engineering, 2012, 14, 116.

49. L. E. van Vlerken, T. K. Vyas and M. M. Amiji, Pharmaceutical research, 2007, 24, 1405-1414.

50. S. Kommareddy and M. Amiji, Journal of pharmaceutical sciences, 2007, 96, 397-407.

51. R. Weissleder, M. Nahrendorf and M. J. Pittet, Nature materials, 2014, 13, 125-138.

52. E. K. U. Larsen, T. Nielsen, T. Wittenborn, H. Birkedal, T. Vorup-Jensen, M. H. Jakobsen, L. Ostergaard, M. R. Horsman, F. Besenbacher, K. A. Howard and J. Kjems, Acs Nano, 2009, 3, 1947-1951.

53. Z. Li, B. Anvari, M. Takashima, P. Brecht, J. H. Torres and W. E. Brownell, Biophysical journal, 2002, 82, 1386-1395.

54. A. Beduneau, Z. Ma, C. B. Grotepas, A. Kabanov, B. E. Rabinow, N. Gong, R. L. Mosley, H. Dou, M. D. Boska and H. E. Gendelman, PloS one, 2009, 4, e4343.

55. K. A. Beningo and Y. L. Wang, Journal of cell science, 2002, 115, 849-856.

56. P. Pacheco, D. White and T. Sulchek, PloS one, 2013, 8, e60989.

57. D. E. Owens, 3rd and N. A. Peppas, International journal of pharmaceutics, 2006, 307, 93-102.

58. M. Diakonova, V. Gerke, J. Ernst, J. P. Liautard, G. van der Vusse and G. Griffiths, Journal of cell science, 1997, 110 ( Pt 10), 1199-1213. 
59. T. H. Sulahian, A. Imrich, G. Deloid, A. R. Winkler and L. Kobzik, Respiratory research, 2008, 9, 59.

60. S. D. Li and L. Huang, J Control Release, 2010, 145, 178-181.

61. J. Mehne, G. Markovic, F. Proll, N. Schweizer, S. Zorn, F. Schreiber and G. Gauglitz, Analytical and bioanalytical chemistry, 2008, 391, 1783-1791.

62. S. Isogai, M. Horiguchi and B. M. Weinstein, Developmental biology, 2001, 230, 278-301.

63. W. Y. Liao, H. J. Li, M. Y. Chang, A. C. Tang, A. S. Hoffman and P. C. Hsieh, Nanoscale, 2013, 5, 11079-11086.

64. M. J. Lee, O. Veiseh, N. Bhattarai, C. Sun, S. J. Hansen, S. Ditzler, S. Knoblaugh, D. Lee, R. Ellenbogen, M. Zhang and J. M. Olson, PloS one, 2010, 5, e9536.

65. S. K. Balasubramanian, K. W. Poh, C. N. Ong, W. G. Kreyling, W. Y. Ong and L. E. Yu, Biomaterials, 2013, 34, 5439-5452.

66. B. I. Tamba, A. Dondas, M. Leon, A. N. Neagu, G. Dodi, C. Stefanescu and A. Tijani, European journal of pharmaceutical sciences : official journal of the European Federation for Pharmaceutical Sciences, 2015, 71, 46-55.

67. E. A. Murphy, B. K. Majeti, L. A. Barnes, M. Makale, S. M. Weis, K. Lutu-Fuga, W. Wrasidlo and D. A. Cheresh, Proc Natl Acad Sci U S A, 2008, 105, 9343-9348.

68. K. Pollinger, R. Hennig, A. Ohlmann, R. Fuchshofer, R. Wenzel, M. Breunig, J. Tessmar, E. R. Tamm and A. Goepferich, Proc Natl Acad Sci U S A, 2013, 110, 6115-6120.

69. M. S. Ehrenberg, A. E. Friedman, J. N. Finkelstein, G. Oberdorster and J. L. McGrath, Biomaterials, 2009, 30, 603-610.

70. F. Alexis, E. Pridgen, L. K. Molnar and O. C. Farokhzad, Molecular pharmaceutics, 2008, 5, 505-515.

71. Y. Sheng, Y. Yuan, C. Liu, X. Tao, X. Shan and F. Xu, Journal of materials science. Materials in medicine, 2009, 20, 1881-1891.

72. Y. Wang and W. Wu, Drug delivery, 2006, 13, 189-192.

73. F. Perche and V. P. Torchilin, Journal of drug delivery, 2013, 2013, 705265.

74. C. L. Lin, F. S. Wang, Y. C. Hsu, C. N. Chen, M. J. Tseng, M. A. Saleem, P. J. Chang and J. Y. Wang, Diabetes, 2010, 59, 1915-1925.

75. Y. Liang, X. Y. Li, E. J. Rebar, P. Li, Y. Zhou, B. Chen, A. P. Wolffe and C. C. Case, The Journal of biological chemistry, 2002, 277, 20087-20094.

76. Y. Wallez, I. Vilgrain and P. Huber, Trends in cardiovascular medicine, 2006, 16, 55-59.

77. I. J. Bettum, K. Vasiliauskaite, V. Nygaard, T. Clancy, S. J. Pettersen, E. Tenstad, G. M. Maelandsmo and L. Prasmickaite, Cancer letters, 2014, 344, 28-39.

78. H. Maeda, J. Wu, T. Sawa, Y. Matsumura and K. Hori, J Control Release, 2000, 65, 271-284.

\section{Figure legends}

Figure 1. ZF injections and establishment of human tumor-like structures. (A) Illustration of injection sites for human cancer cells and NPs. The red line illustrates the dissemination route for cancer cells via blood vessels to the most frequent site of extravasation (White Square) where tumor-like structures were established. The entire vasculature is visible as a result of circulating fluorescent nanoparticles. (B) The melanoma cell line Melmet 5 (red) had the capacity to establish multiple tumor-like structures in the tail. (C) A Melmet 5 tumor-like structure (red) in the tail showing its typical orientation relative to 
the vasculature (green), in between blood vessels. (D) The vasculature (green) is pushed aside where the Melmet 5 cells are growing (arrow). (E) HEK293 cells established single tumorlike structures in the tail. (F) A HEK293 tumor-like structure (red) and its orientation relative to the vasculature (green). These cells had the capacity to grow peripheral to the vasculature (arrow). (G) The HEK293 cells also pushed the vasculature aside (arrow) when located in between blood vessels (green). (H) Quantification of Melmet 5 tumor-like structure sizes in individual embryos over a period of $6 \mathrm{dpi}(\mathrm{p}<0.05)$. (I) Quantification of HEK293 tumor-like structure sizes in individual embryos over a period of 6 dpi $(p>0.05)$. $N=6$. Scale bars: 100 $\mu \mathrm{m}(\mathbf{C}, \mathbf{D}, \mathbf{F}, \mathbf{G})$.

Figure 2. NoPEG PSNPs had short circulation times in zebrafish embryos. (A) NoPEG blue fluorescent $1000 \mathrm{~nm}$ PSNPs adhered to the endothelium (green) shortly after injection into $\operatorname{Tg}\left(f l i 1\right.$ :EGFP) ${ }^{\boldsymbol{y} \boldsymbol{1}}$ embryos having green fluorescent vasculature. (B) 20 seconds post injection of fluorescent $200 \mathrm{~nm}$ NoPEG PSNPs (green) they were circulating (asterisk) but also adhered to the endothelium, as evident by intense green dots (red arrows). (C) 140 seconds post injection low levels (compared to (B)) of NoPEG PSNPs (green) were in circulation (white asterisk). NoPEG PSNPs adhered to the DLAV (white arrow), caudal artery (yellow asterisk), caudal vein (red asterisk) and the small vessels in between them (red arrow). Very little adhesion was observed in the intersegmental vessels (yellow arrow). (D) 20 minutes post injection NoPEG PSNPs (green) were completely cleared from the circulation. A speckled pattern appeared as a result of NoPEG PSNPs (green) adhering to endothelial cells. (E) Circulating NoPEG fluorescent liposomes (green) in a wild type embryo results in a complete representation of the vasculature. Low levels of liposomes were infrequently observed to adhere to the endothelium (white arrow). (F) 20 hours post injection into mpeg cherry embryos having red fluorescent macrophages; NoPEG liposomes (green) were all cleared from circulation and taken up by the red macrophages (yellow dots, arrows). All experiments $\mathrm{N}=10$, representative images are shown. Scale bars: $200 \mu \mathrm{m}$ (A-C, E,F); 100 $\mu \mathrm{m}$ (d).

Figure 3. In vitro characterization of the PEGylation effect. (A) Transmission EM image of negatively stained $200 \mathrm{~nm}$ PEG liposomes (Table 1). (B) High levels of $200 \mathrm{~nm}$ NoPEG PSNPs (green) were taken up by RAW macrophages (Figure 3B-1). Conversely, the $200 \mathrm{~nm}$ 
PEG PSNPs (green) were taken up in much lower levels (Figure 3B-2). (C) Flow cytometry analysis showed a 2-fold higher uptake by macrophages of NoPEG PSNPs (green) compared to PEG PSNPs (yellow). Control macrophages defining the baseline are shown in grey. (D) Green fluorescent NoPEG (Figure 3D-1) and PEG (Figure 3D-2) liposomes were taken up by RAW macrophages in roughly equal amounts after 10 minute of incubation. Scale bars: $1 \mu \mathrm{m}$ (A); $50 \mu \mathrm{m}(\mathbf{B}, \mathbf{D})$.

Figure 4. Quantification of the PEGylation effect using optical tweezers. (A) NoPEG $1000 \mathrm{~nm}$ PSNPs adhered more frequently to RAW macrophages than NoPEG $500 \mathrm{~nm}$ PSNPs $(\mathrm{p}=<0.01)$. (B) A NoPEG $1000 \mathrm{~nm}$ PSNP stimulated a macrophage to engulf it within a minute after the first contact (left panel, arrow) while a PEG PSNP of the same size did not stimulate such a response (right panel, arrow). (C) The presence of PEG on the surface of PSNPs eliminated the size effect, as $1000 \mathrm{~nm}$ and $500 \mathrm{~nm}$ PEG PSNPs showed similar adhesion levels to RAW macrophages $(p=>0.05)$. (D) Pre-incubation of PSNPs in serum did not affect binding profiles to RAW macrophages. PEG coating prevented binding, while serum incubation with NoPEG PSNPs did not result in increased binding, as compared to (A) $(\mathrm{p}=<0.01)$. (E) PEGylation of PSNPs inhibited adhesion of these beads to cancer cells. Preincubation of PSNPs in serum did not interfere with the PEG-effect as all adhesion to Melmet 5 was blocked. The presence of serum proteins lowered the binding of NoPEG PSNPs to Melmet 5 as PBS-incubated NoPEG PSNPs, lacking serum proteins, displayed higher level of adhesion. Scale bars: $10 \mu \mathrm{m}(\mathbf{B})$.

Figure 5. PEGylation prolonged NP circulation time in zebrafish embryos. (A) $200 \mathrm{~nm}$ PEG PSNP (green) in circulation of a wild-type embryo 20 seconds post injection (white asterisk). Adhesion of these NPs to the vasculature, evident as green intense spots, was only observed in the small vessels (red arrow) between the caudal artery (yellow asterisk) and caudal vein (red asterisk). (B) 140 seconds post injection into a wild type embryo relatively high level of green fluorescent PEG PSNPs (compared to (A)) were still in circulation (white asterisk). These NPs did not adhere to the DLAV (white arrow), nor to the caudal artery (yellow asterisk) nor caudal vein (red asterisk) and only visibly adhered to the small vessels between them (red arrow, green intense spots). (C) Maximum circulation time of PEG PSNPs (green) was 60 minutes. They were not associated with, or taken up by macrophages (red) in 
the mpeg cherry embryo. (D) PEG liposomes (green) injected into an mpeg cherry zebrafish embryo with fluorescent macrophages (red) circulated $24 \mathrm{~h}$ post injection. Fractions of liposomes were taken up by macrophages (yellow, arrow) but the majority was still in circulation, as evident by making the vasculature visible. (E) $46 \mathrm{~h}$ post-injection a full representation of the vasculature of a wild type embryo was observed as a consequence of circulating liposomes (green). They were continuously but slowly taken up by macrophages (green dots, arrows). (F) By $70 \mathrm{~h}$ post injection all PEG liposomes was cleared from circulation of a wild type embryo as they were taken up by macrophages (green dots, arrows). Importantly, no adhesion of liposomes to the endothelium was observed. All experiments $\mathrm{N}=$ 10, representative images are shown. Scale bars: $200 \mu \mathrm{m}$ (A-F).

Figure 6. Liposomes accumulated passively into human tumor-like structures. (A) 2 dpi Melmet 5 tumor-like structures (red) accumulated liposomes (green) after $2 \mathrm{~h}$ of circulation. (B) An image showing the tail of a wild type embryo. Liposomes (green) only accumulated at the site of the Melmet 5 tumor-like structures (red). (C) Tumor-like structures comprised of HEK293 cells (red) also had the capacity to accumulate liposomes (green). (D) A control embryo injected with liposomes (green), without cancer cells, show the distribution of liposomes after $5 \mathrm{~h}$ circulation. Minute levels of liposomes were taken up by macrophages (arrows) and were only visible with considerably higher exposure time than the images in (AC). (E) 3D view of a confocal stack of a 2 dpi Melmet 5 tumor-like structure (red) with accumulated liposomes (green) after $3 \mathrm{~h}$ of circulation. Liposomes seemed to associate tightly with the cancer cells, mostly at the periphery of the tumor-like structure. A sub-fraction of the liposomes were able to penetrate deeper into the tumor-like structure (arrow). (F) 3D view of a confocal stack of a 2 dpi HEK293 tumor-like structure (red) with accumulated liposomes (green) after $5 \mathrm{~h}$ of circulation. The liposomes had a loose association with the tumor-like structure as they concentrated in the area around the cancer cells, and did not interact with the cancer cells directly. Experiments shown in A-D, $\mathrm{N}=8$. Representative images are shown. Scale bars: $100 \mu \mathrm{m}$ (A, C); $300 \mu \mathrm{m}$ (B); $200 \mu \mathrm{m}$ (D); $30 \mu \mathrm{m}$ (E, F).

Supplementary Figure 1. No leakage of dextran into tumor-like structures. (A) Confocal stack of a Melmet 5 tumor-like structure (red) surrounded by the vasculature (green) in which the dextran flows (blue). The dotted arrow indicates the direction of the blood flow. We could 
not observe any leakage of $10 \mathrm{kDa}$ dextran into the tumor-like structure. A blood vessel behind the tumor-like structure (arrow) is transporting dextran but it is not leaking out. (B) Confocal image of a HEK293 tumor-like structure (red, asterisk) located next to a blood vessel (green) transporting dextran (blue). The dotted arrow indicates the direction of the blood flow. No leakage of dextran into the tumor-like structure could be observed. $\mathrm{N}=4$. Scale bars: $30 \mu \mathrm{m}$.

Supplementary video 1. $200 \mathrm{~nm}$ green fluorescent NoPEG PSNPs in zebrafish embryo circulation 20 seconds post injection.

Supplementary video 2. $200 \mathrm{~nm}$ green fluorescent NoPEG PSNPs in zebrafish embryo circulation 140 seconds post injection

Supplementary video 3. $1000 \mathrm{~nm}$ NoPEG PSNP adhering to a RAW macrophage in vitro.

Supplementary video 4. $1000 \mathrm{~nm}$ PEG PSNP do not adhere to a RAW macrophage in vitro.

Supplementary video 5. $200 \mathrm{~nm}$ green fluorescent PEG PSNPs in zebrafish circulation 20 seconds post injection

Supplementary video 6. $200 \mathrm{~nm}$ green fluorescent PEG PSNPs in zebrafish circulation 140 seconds post injection

Supplementary video 7. $200 \mathrm{~nm}$ green PEG liposomes in zebrafish embryo circulation $24 \mathrm{~h}$ post injection.

Supplementary video 8. $200 \mathrm{~nm}$ PEG green liposomes in zebrafish embryo circulation $46 \mathrm{~h}$ post injection.

Supplementary video 9. $200 \mathrm{~nm}$ PEG green liposomes taken up by macrophages $70 \mathrm{~h}$ post injection

Supplementary video 10. $200 \mathrm{~nm}$ green PEG liposomes circulating in zebrafish embryo with red tumor-like structures.

Supplementary video 11. $200 \mathrm{~nm}$ green liposomes accumulated in Melmet 5 tumor-like structure. Tumor-like structures are invisible but the embryo is the same as in Figure 6B where the tumor-like structures can be seen.

Supplementary video 12. 3D view of a confocal stack (ImageJ) of a red Melmet 5 tumor-like structure with accumulated green liposomes.

Supplementary video 13. 3D view of a confocal stack (ImageJ) of a red HEK293 tumor-like structure with accumulated green liposomes. 

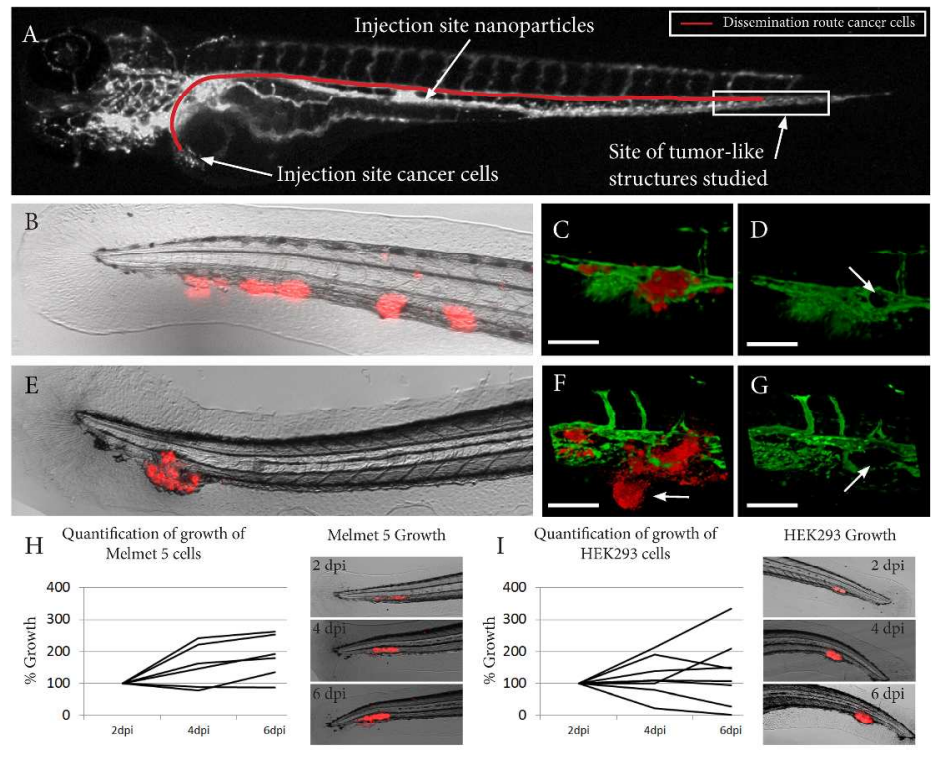

Figure 1

$297 \times 420 \mathrm{~mm}(300 \times 300$ DPI) 


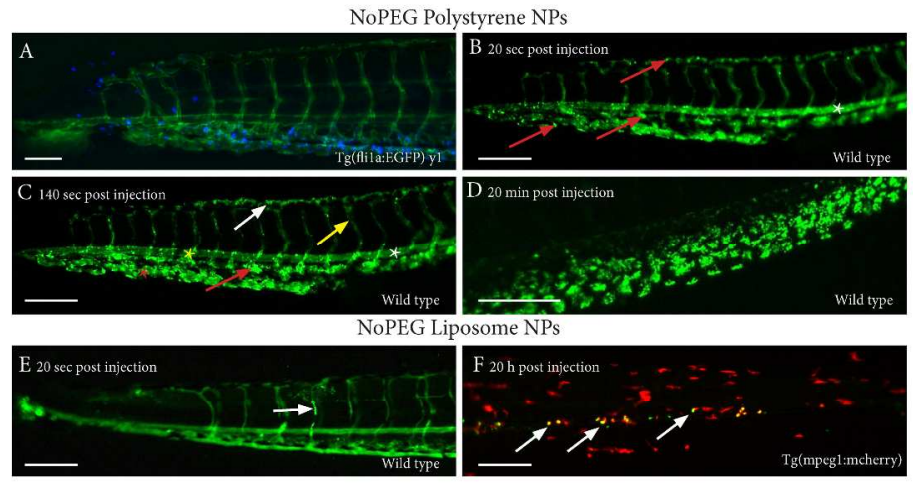

Figure 2 


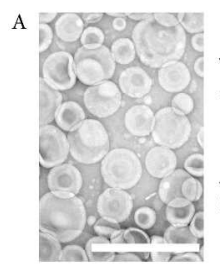

C

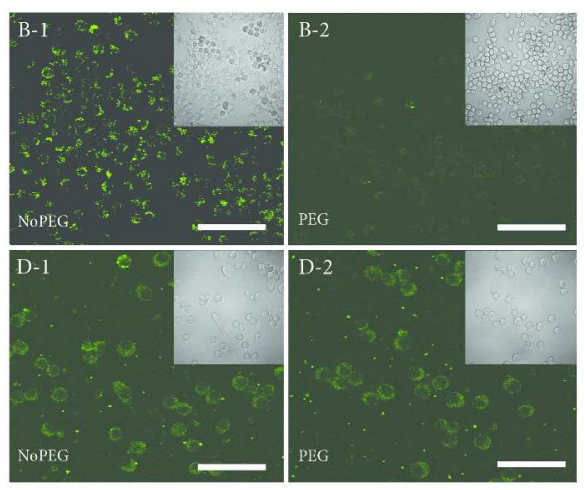

Figure 3

$297 \times 420 \mathrm{~mm}(300 \times 300$ DPI $)$ 

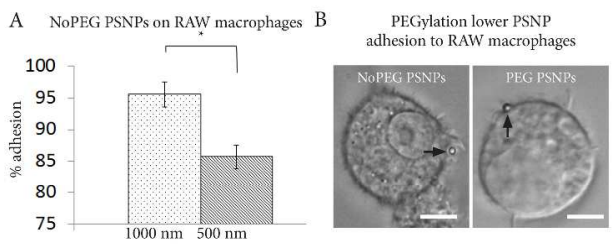

C PEG PSNPs on RAW macrophages

D

$1000 \mathrm{~nm}$ PSNPs on RAW Macrophages

E $1000 \mathrm{~nm}$ PSNPS on Melmet 5 cancer cells
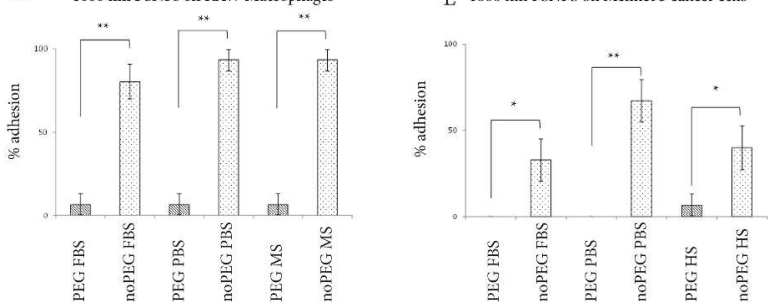

Figure 4 


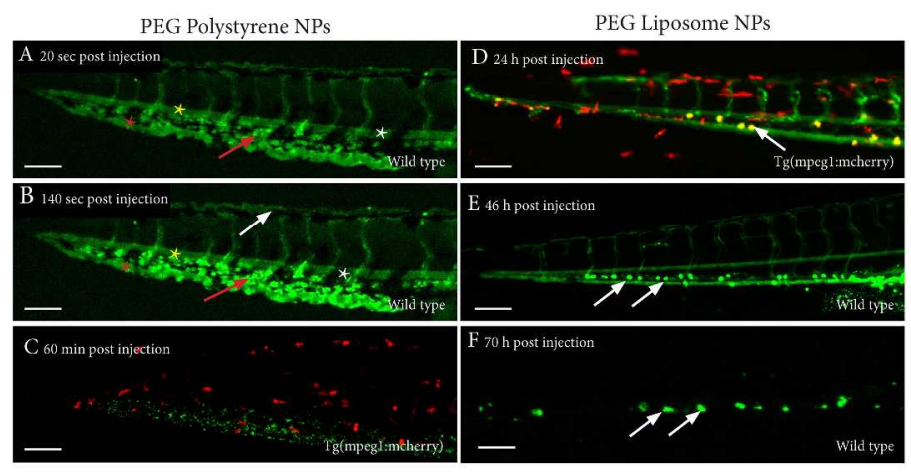

Figure 5

$297 \times 420 \mathrm{~mm}(300 \times 300$ DPI $)$ 

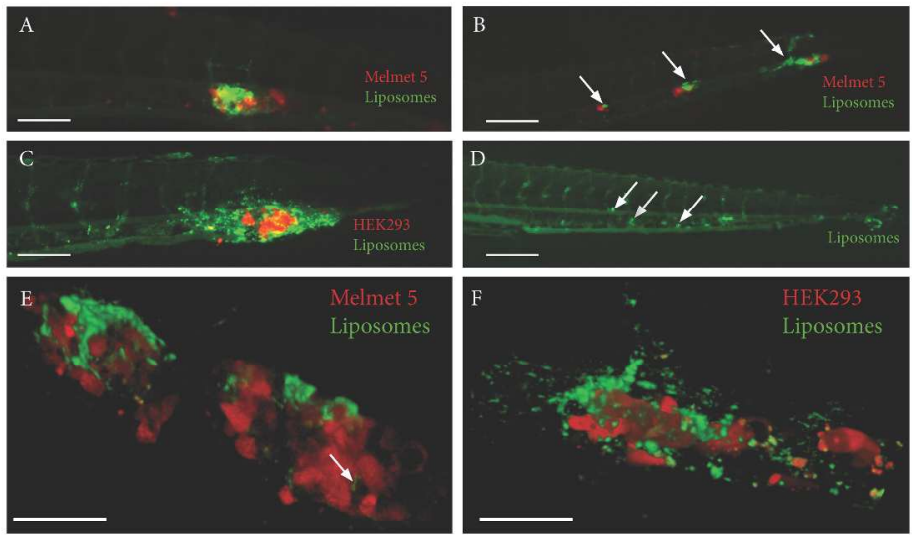

Figure 6

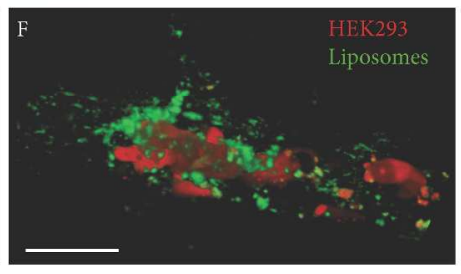

$297 \times 420 \mathrm{~mm}(300 \times 300$ DPI $)$ 